Article

\title{
Binding of calcium and magnesium ions to chromophoric dis- solved organic matter (CDOM): A combination of steady-state and time-resolved fluoresce study
}

\author{
Juan Liu, Ruiya Zhou and Xu Zhang * \\ Department of Environmental Science, School of Resources and Environmental Science, Wuhan University, \\ Wuhan, 430079, P.R. China \\ * Correspondence: xuzhangwhu@gmail.com
}

\begin{abstract}
Revealing the binding properties of calcium ion $\left(\mathrm{Ca}^{2+}\right)$ and magnesium ion $\left(\mathrm{Mg}^{2+}\right)$ to chromophoric dissolved organic matter (CDOM) facilities understanding the effect of natural water composition on the photophysics of dissolved organic matter. Steady-state and time-resolved fluorescence spectrometry, and dynamic light scattering were applied to investigate the fluorescence quenching process of CODM by $\mathrm{Ca}^{2+}$ and $\mathrm{Mg}^{2+}$. The binding of $\mathrm{Ca}^{2+}$ and $\mathrm{Mg}^{2+}$ preferred terrestrial CDOM to aquatic CDOM. The fluorescence quenching of CDOM by cations mainly occurred in a static process, which was based on the fact that the decrease of steady-state fluorescence intensity was greater than fluorescence lifetime. The fluorescence quenching was profound under longer excitation and emission wavelength. The binding constant $(K, \mathrm{~L} / \mathrm{mol})$ for $\mathrm{Ca}^{2+}$ to CDOM from terrestrial source ranged from 4.29 to $5.09(\lg K)$, which was approximately one order of magnitude higher than that of $\mathrm{Mg}^{2+}$ to $\mathrm{CDOM}$ (3.86 to 4.56). Fluorescence decay became faster in the presence of $\mathrm{Ca}^{2+}$ and $\mathrm{Mg}^{2+}$. Lifetime distribution of CDOM excited states shifted to small value side in the presence of metal ions, particularly for $\mathrm{Ca}^{2+}$, indicating fluorescence quenching of CDOM mainly through the interaction of $\mathrm{Ca}^{2+} / \mathrm{Mg}^{2+}$ with relatively long-lived fluorophores.
\end{abstract}

Keywords: CDOM; calcium; magnesium; fluorescence quenching; lifetime distribution

\section{Introduction}

Natural organic matter (NOM) is ubiquitous in natural water. NOM plays a key role in biological and chemical processes because of the direct competition for solar irradiance and the subsequently generated reactive species [1-5]. Metal ions tend to bind to NOM mainly through the phenolic and carboxylic functional groups.[6] The binding of metal ions to NOM not only altered the bioavailability of metal ions but also affected the photophysical and photochemical properties of NOM $[5,7,8]$.

Among various metal ions, copper ion $\left(\mathrm{Cu}^{2+}\right)[9-11]$ and mercury ion $\left(\mathrm{Hg}^{2+}\right)[12,13]$, were the most frequently investigated species. Previous studies demonstrated that binding constants between $\mathrm{Cu}^{2+}, \mathrm{Hg}^{2+}$, and $\mathrm{NOM}$ could be up to $10^{6} \mathrm{~L} / \mathrm{mol}[14,15]$, leading to a decreased fluorescence intensity of NOM. The binding constants were dependent on NOM source (structure) and experimental conditions such as solution $\mathrm{pH}$ and salinity $[9,16,17]$. The competition of co-existing cations for binding sites in NOM was used to explain the inhibition effect of salinity on the binding of conducted metal ions to NOM $[9,18-20]$. For example, the presence of up to $11 \times 10^{-6} \mathrm{~mol} / \mathrm{L} \mathrm{Ca}^{2+}$ broke Hg-NOM complex and increased the fluorescence intensity, whereas $\mathrm{Ca}^{2+}$ exhibited no apparent effect on NOM fluorescence intensity [19]. However, the binding properties of $\mathrm{Ca}^{2+}$ and $\mathrm{Mg}^{2+}$ to NOM have not been fully documented.

Notably, binding properties of metal ions to NOM (components) were determined by Excitation-Emission matrix (EEM) followed with parallel factor analysis (PARAFAC). The knowledge about the effects of metal ions on NOM's fluorescence lifetime is still quite 
limited [21]. In our previous study[22], we found that fluorophores with relatively short lifetime $(<1 \mathrm{~ns})$ dominated CDOM (the major composition of NOM) excited populations, while these short-lived excited states could not be well documented by steady-state fluorescence because of their minor contribution. Static quenching through the formation of metal-NOM complex was proposed to explain the fluorescence quenching. Nevertheless, certain fluorophores had relatively long lifetime (approximately $10 \mathrm{~ns}$ ), collision quenching would not be excluded in the presence of millimolar level metal ions.

In this study, interactions between $\mathrm{Ca}^{2+}$ and $\mathrm{Mg}^{2+}$ and CDOM (aquatic and terrestrial source) were systematically investigated by steady-state and time-resolved fluorescence spectrometry. The first objective is to quantify fluorescence quenching extents and determine binding constant. The second objective is to reveal the mechanism for fluorescence quenching based on the effects of $\mathrm{Ca}^{2+}$ and $\mathrm{Mg}^{2+}$ on the quenching of steady-state fluorescence intensity and fluorescence lifetime, and the change of CDOM dispersity.

\section{Materials and Methods}

\subsection{Chemicals}

Analytical grade $\mathrm{CaCl}_{2}$ and $\mathrm{MgSO}_{4}$ were purchased from Sinopharm Chemical Reagent Co., Ltd. (Shanghai, China) and used as received. CDOM reference materials, Suwannee River natural organic matter (SRNOM, Lot 2R101N), Suwannee River Humic Acid Standard III (SRHA, Lot 3S101H), Elliott Soil HA Standard IV (ESHA, Lot 5S102H), and Pahokee Peat Humic Acid Standard (PPHA, Lot 1S103H), were purchased from the International Humic Substance Society. CDOM was added to $\mathrm{pH} 10.0$ water and stirred for two hours. Then, $\mathrm{pH}$ of the CDOM solution was adjusted to 7.0 and filtered by a $0.22 \mu \mathrm{m}$ nylon membrane (Shanghai Xingya Purification material Factory, China). All the CDOM stock solutions were stored in dark at $4^{\circ} \mathrm{C}$ and used within one month. The concentrations of CDOM stock solutions were analyzed on an Elementa total organic carbon analyzer (Vario TOC; Elementar, Langenselbold, Germany).

\subsection{Experimental procedure}

Working solutions of CDOM (10 mg C/L), $\mathrm{Ca}^{2+}(0-30 \mathrm{mg} / \mathrm{L})$, and $\mathrm{Mg}^{2+}(0-70 \mathrm{mg} / \mathrm{L})$ were prepared by dilution. The resulting solutions were shaken at $25 \pm 0.2^{\circ} \mathrm{C}$ for at least 12 hours to reach binding equilibrium. The $\mathrm{pH}$ values of the working solutions were adjusted to 7.5 by phosphate buffer. The ionic strength was adjusted to $20 \mathrm{mM}$ for all working solutions.

\subsection{Spectra recording method}

Absorption spectra: The absorption spectra were recorded with an ultraviolet (UV)visible spectrometer (UV 2550; Shimadzu, Tokyo, Japan) at $25 \pm 0.5^{\circ} \mathrm{C}$. The optical path length of the cuvette was $1 \mathrm{~cm}$.

Steady-state fluorescence spectra of CDOM solutions: Steady-state fluorescence spectra of CDOM were recorded with either an Edinburgh FS-5 or a Horiba FluoroLog-3 fluorimeter. The excitation (Ex) and emission (Em) wavelength range for the excitation emission matrix (EEM) fluorescence spectra of CDOM in the absence and presence of $\mathrm{Ca}^{2+}$ and $\mathrm{Mg}^{2+}$ were 250-600 $\mathrm{nm}$ and 270-750 nm, respectively. The stepsize was $5 \mathrm{~nm}$ and 2 $\mathrm{nm}$ for excitation and emission, respectively. The slit size was $5 \mathrm{~nm}$. The dwell time was $0.100 \mathrm{~s}$. Fluorescence intensity was corrected using factory-measured correction files. Ultrapure water was used for background and scatter subtraction, and inner-filter effect was also corrected.

To get a more precise fluorescence quenching efficiency, the single emission profile (400-800 nm, increments of $1 \mathrm{~nm}$, dwell time was $0.100 \mathrm{~s}$ ) was recorded at excitation wavelengths of 375,440 , and $550 \mathrm{~nm}$, and the intensity correction followed the same protocol for EEM fluorescence spectra. 
Time-resolved fluorescence spectra of CDOM solutions: Time-resolved fluorescence spectra of CDOM were measured with a FluoTime 200 equipment (PicoQuant $\mathrm{GmbH}$, Berlin, Germany) at $25 \pm 1^{\circ} \mathrm{C}$. The excitation source was a picosecond laser diode (LDH-P-C-375B for $375 \mathrm{~nm}$, LDH-P-C-440B for $440 \mathrm{~nm}$ ). The fluorescence decay of CDOM was detected using a PMA hybrid 07 detector and recorded in a Picoharp 300 time-correlated single-photon counter. The maximum intensity of CDOM was 10, 000 counts, and the counting rate was less than $1 \%$ of the excitation rate to avoid pile-up problem. The instrument response function (IRF) was recorded using a Ludox solution by recording the scattered light at $375 \mathrm{~nm}$ or $440 \mathrm{~nm}$. Lifetime distribution analysis was applied to model emission decays of CDOM with FAST program (Version 3.5, Edinburgh). Detailed procedures for data analysis and fitting criteria were reported in a previous study.[22]

Hydrodynamic diameters of CDOM solutions: Hydrodynamic diameters of CDOM solutions (ESHA: $60 \mathrm{mg} \mathrm{C/L}$; PPHA: $100 \mathrm{mg} \mathrm{C/L}$ ) in the presence and in the absence of $\mathrm{Ca}^{2+}$ and $\mathrm{Mg}^{2+}$ were determined using a Malvern Zen 3700 Zetasizer (Worcestershire, UK).

\section{Results}

\subsection{Changes of $C D O M$ 's absorption spectra with $\mathrm{Ca}^{2+}$ and $\mathrm{Mg}^{2+}$}

As shown in Figure S1, the absorption spectra of ESHA and PPHA did not change much in the presence of $\mathrm{Ca}^{2+}$ or $\mathrm{Mg}^{2+}$, particularly in the wavelength longer than $400 \mathrm{~nm}$. An inconspicuous but discernible change of absorption spectra was reported for the binding of $\mathrm{Ca}^{2+}$ to SRHA [23]. Notably, light scattering became notable for ESHA in the presence of high $\mathrm{Ca}^{2+}$ (such as $20 \mathrm{mg} / \mathrm{L}$ ). The increase of light scattering was in line with the change of hydrodynamic size with $\mathrm{Ca}^{2+}$ and $\mathrm{Mg}^{2+}$ (Figure S2). In the presence of $\mathrm{Ca}^{2+}$ or $\mathrm{Mg}^{2+}$, the hydrodynamic size of ESHA and PPHA became larger, particularly for ESHA. Similar results were also reported for fulvic acid after binding $\mathrm{Cu}^{2+}, \mathrm{Pb}^{2+}$, or $\mathrm{Cd}^{2+}$ [24], which resulted from cation bridge effects [25]. 

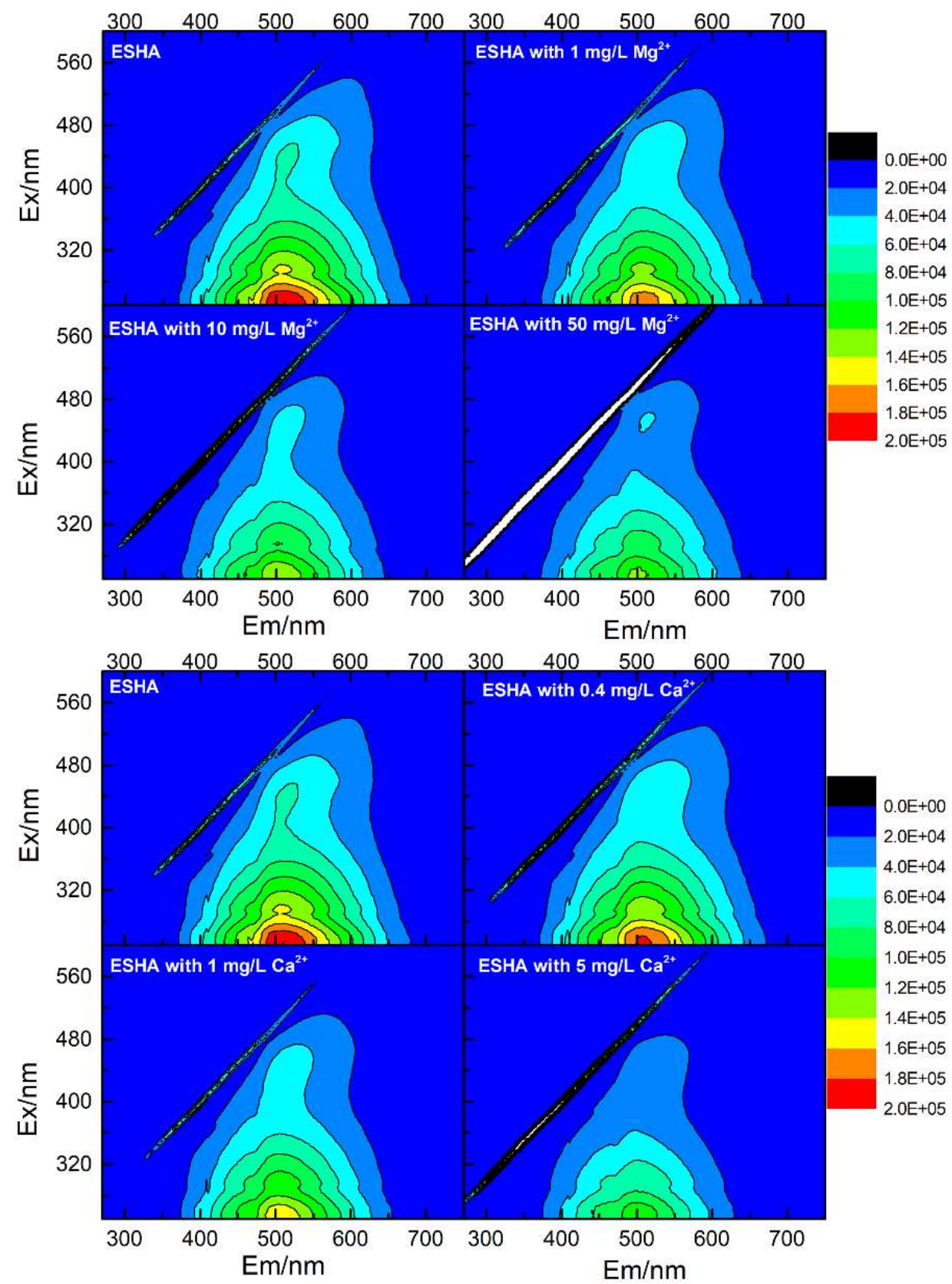

Figure 1. Effects of $\mathrm{Mg}^{2+}$ or $\mathrm{Ca}^{2+}$ on the EEM spectra of ESHA (10 mg C/L) aqueous solution.

\subsection{Changes of CDOM's emission spectra with $\mathrm{Ca}^{2+}$ and $\mathrm{Mg}^{2+}$}

Compared with the slight change of absorption spectra, the steady-state fluorescence intensity of ESHA and PPHA significantly decreased with an increase of $\mathrm{Ca}^{2+}$ or $\mathrm{Mg}^{2+}$ concentration in the whole conducted spectra range (Figure 1). The inhibition effect of $\mathrm{Ca}^{2+}$ was more evident than $\mathrm{Mg}^{2+}$, while the decrease intensity of ESHA was more profound than PPHA (Figure S3). 

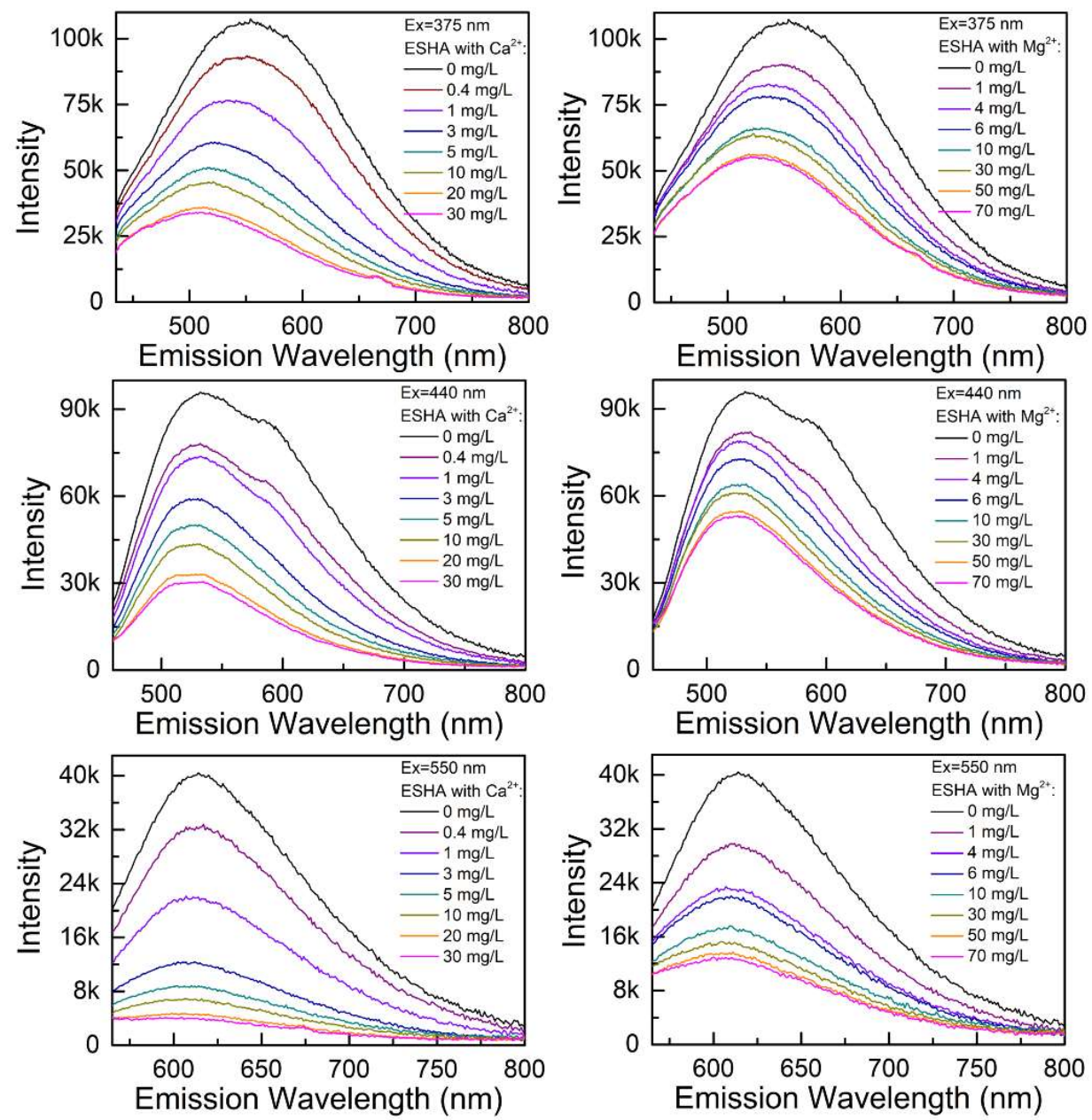

Figure 2. Effects of $\mathrm{Mg}^{2+}$ or $\mathrm{Ca}^{2+}$ on the steady-state fluorescence spectra of ESHA $(10 \mathrm{mg} \mathrm{C} / \mathrm{L})$ aqueous solution at the excitation of 375,440 , and $550 \mathrm{~nm}$.

As demonstrated in Figure 2, under the excitation of 375, 440, and $550 \mathrm{~nm}$, with an increase of $\mathrm{Ca}^{2+}(0-30 \mathrm{mg} / \mathrm{L})$ or $\mathrm{Mg}^{2+}(0-70 \mathrm{mg} / \mathrm{L})$, the fluorescence intensity of ESHA decreased gradually, and remained almost unchanged at high $\mathrm{Ca}^{2+}$ concentration $(>20 \mathrm{mg} / \mathrm{L})$ or high $\mathrm{Mg}^{2+}$ concentration (>50 mg/L). The change of PPHA fluorescence intensity with $\mathrm{Ca}^{2+}$ and $\mathrm{Mg}^{2+}$ was analogous to ESHA, but to a less extent (Figure S4). Notably, $\mathrm{Ca}^{2+}$ and $\mathrm{Mg}^{2+}(20 \mathrm{mg} / \mathrm{L}$ ) did not quench the fluorescence of either SRNOM or SRHA (data not shown). 

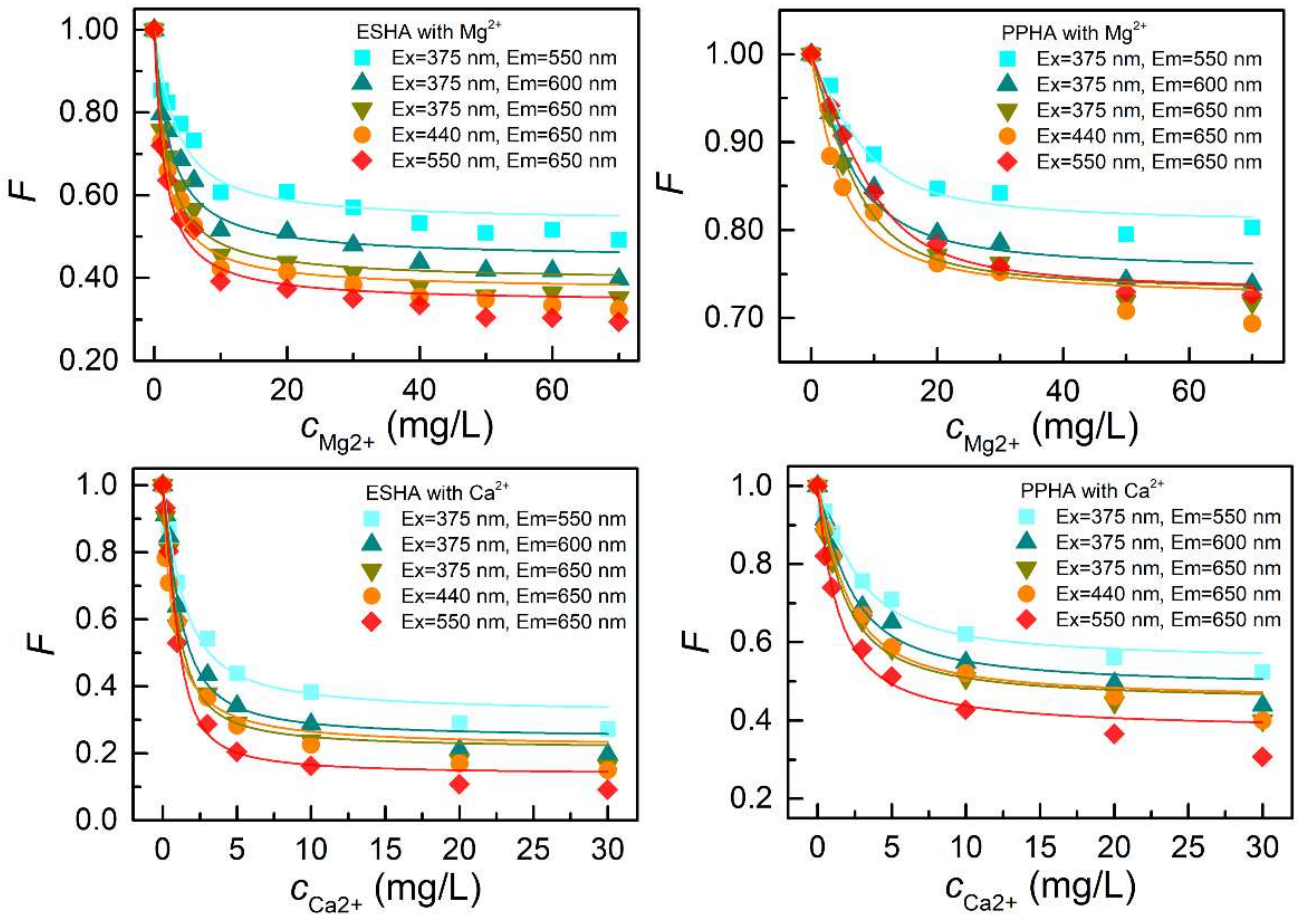

Figure 3. Changes of steady-state fluorescence intensity of ESHA (10 mg C/L) and PPHA (10 mg $\mathrm{C} / \mathrm{L}$ ) with $\mathrm{Mg}^{2+}$ and $\mathrm{Ca}^{2+}$ concentration. Curves represent the fitting of experimental data with modified Ryan-Weber equation [26].

Table 1. Binding constant $\left(K, 10^{4} \mathrm{~L} / \mathrm{mol}\right)$ of $\mathrm{Ca}^{2+}$ and $\mathrm{Mg}^{2+}$ to ESHA and PPHA.

\begin{tabular}{cccccc}
\hline \multirow{2}{*}{ Ex (nm) } & \multirow{2}{*}{ Em (nm) } & \multicolumn{2}{c}{ ESHA } & \multicolumn{2}{c}{ PPHA } \\
\cline { 3 - 6 } & & $\mathrm{Ca}^{2+}$ & $\mathrm{Mg}^{2+}$ & $\mathrm{Ca}^{2+}$ & $\mathrm{Mg}^{2+}$ \\
\hline \multirow{3}{*}{375} & 550 & 4.69 & 1.02 & 2.85 & 0.83 \\
& 600 & 6.89 & 1.15 & 2.98 & 0.90 \\
440 & 650 & 9.02 & 1.39 & 3.49 & 1.13 \\
550 & 650 & 6.17 & 1.61 & 3.43 & 0.86 \\
& 650 & 12.38 & 1.72 & 3.65 & 1.36 \\
\hline
\end{tabular}

Modified Ryan-Weber equation was applied to calculate binding constant $(K)$ between metal ions and CDOM (Figure 3) [26]. As listed in Table 1, $\lg K$ was excitation and emission wavelength dependent, which was larger at longer excitation and emission wavelength. For instance, under the excitation of $375 \mathrm{~nm}, K$ for binding of $\mathrm{Mg}^{2+}$ and $\mathrm{Ca}^{2+}$ to ESHA at emission $650 \mathrm{~nm}$ was 1.36 and 1.92 times that for emission at $550 \mathrm{~nm}$, respectively. With excitation wavelength increased from $375 \mathrm{~nm}$ to $550 \mathrm{~nm}(\mathrm{Em}=650 \mathrm{~nm}), K$ for binding of $\mathrm{Mg}^{2+}$ to ESHA and $\mathrm{Ca}^{2+}$ to ESHA increased from $1.39 \times 10^{4}$ to $1.72 \times 10^{4} \mathrm{~L} / \mathrm{mol}$ and from $9.02 \times 10^{4}$ to $12.38 \times 10^{4} \mathrm{~L} / \mathrm{mol}$. 

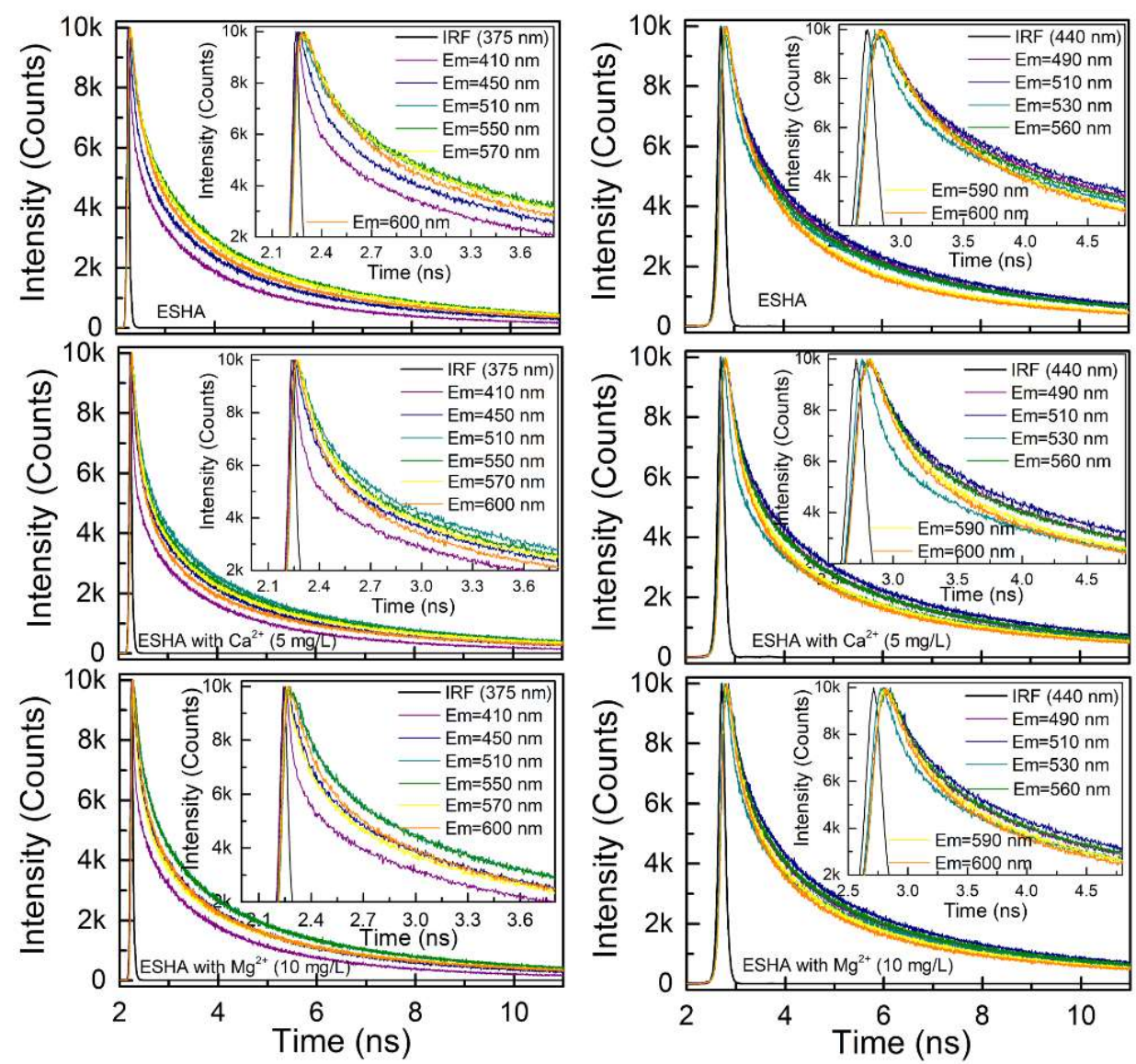

Figure 4. Effects of $\mathrm{Mg}^{2+}(10 \mathrm{mg} / \mathrm{L})$ or $\mathrm{Ca}^{2+}(5 \mathrm{mg} / \mathrm{L})$ on the time-resolved fluorescence spectra of ESHA (10 $\mathrm{mg} \mathrm{C/L})$ aqueous solution at excitation of 375 and $440 \mathrm{~nm}$.

\subsection{Changes of $C D O M$ 's emission decays with $\mathrm{Ca}^{2+}$ and $\mathrm{Mg}^{2+}$}

Emission decays of $\mathrm{CDOM}$ were only slightly affected by $\mathrm{Ca}^{2+}$ and $\mathrm{Mg}^{2+}$. For example, emission decays of ESHA were not affected by either $5 \mathrm{mg} / \mathrm{L} \mathrm{Ca}^{2+}$ or $10 \mathrm{mg} / \mathrm{L} \mathrm{Mg}^{2+}$ (Figure 4). Analogous results were found in the case of PPHA (Figure S5). Since it was proved that results obtained from multi-exponential analysis of fluorescence decays had no physical meaning [22], lifetime distribution analysis was applied to quantify the effects of $\mathrm{Ca}^{2+}$ and $\mathrm{Mg}^{2+}$ on the deactivation of excited states in CDOM. 

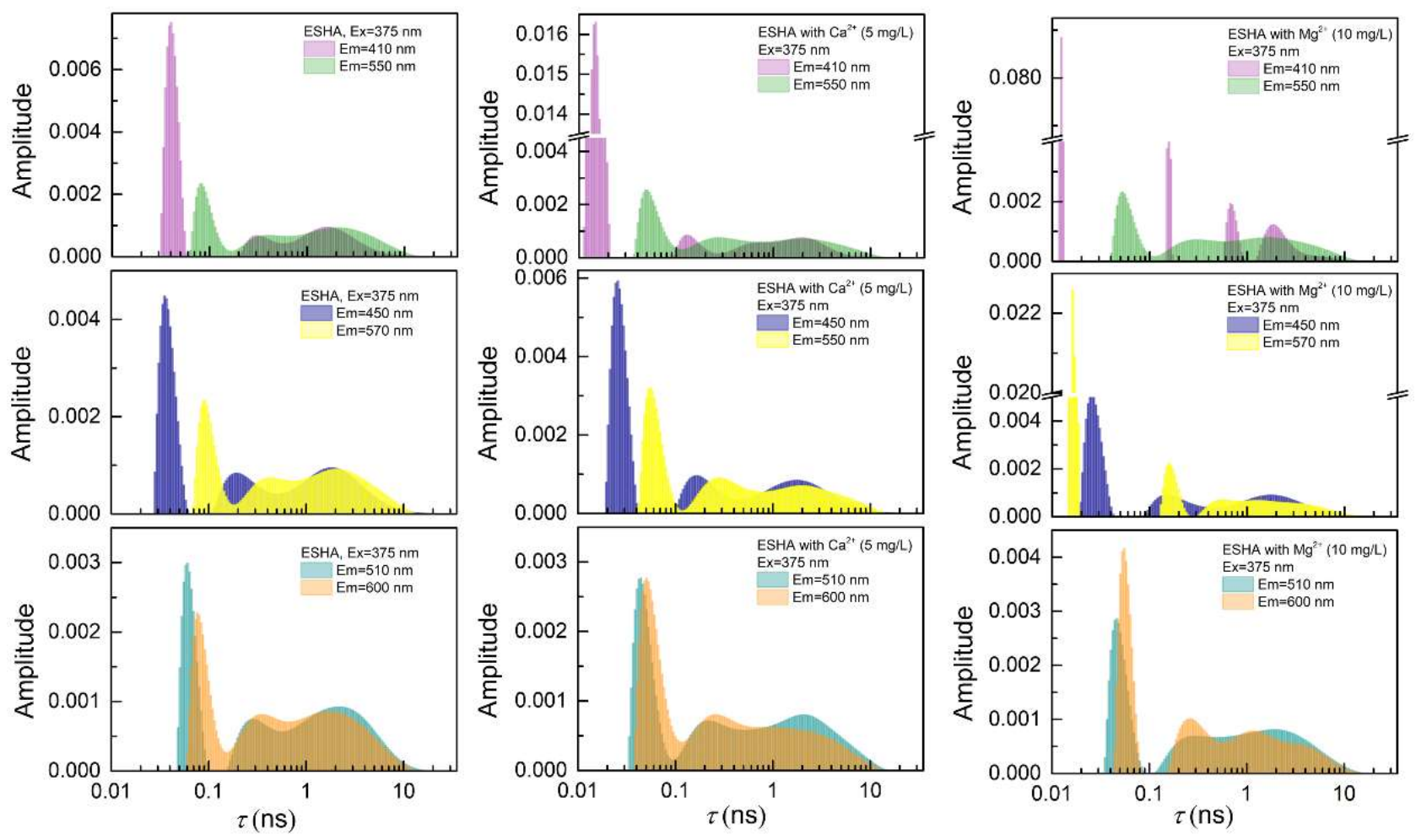

Figure 5. Lifetime distributions for emission decays of ESHA (10 mg C/L) aqueous solution at excitation of 375 and 440 $\mathrm{nm}, \mathrm{Mg}^{2+}(10 \mathrm{mg} / \mathrm{L})$ or $\mathrm{Ca}^{2+}(5 \mathrm{mg} / \mathrm{L})$.

As demonstrated in Figure 5, compared with the lifetime distribution of ESHA in the absence of cations, lifetime for excited states of CDOM shifted to the smaller value side regardless of excitation wavelength. The result demonstrated the formation of shorterlived species in the presence of $\mathrm{Ca}^{2+}$ and $\mathrm{Mg}^{2+}$, suggesting the change of CDOM excited states composition. Moreover, the change of fluorescence decays and reduce of fluorescence lifetimes were more evident at $\mathrm{Ca}^{2+}$ concentration of $20 \mathrm{mg} / \mathrm{L}$ and $\mathrm{Mg}^{2+}$ concentration of $40 \mathrm{mg} / \mathrm{L}$ (Figure 6). Consistent with the relatively smaller change of steady-state fluorescence, the deactivation kinetics of excited states in PPHA was slightly changed in the presence of $\mathrm{Ca}^{2+}$ and $\mathrm{Mg}^{2+}$ supported by the bare change of lifetime distribution (Figures S6, S7). 

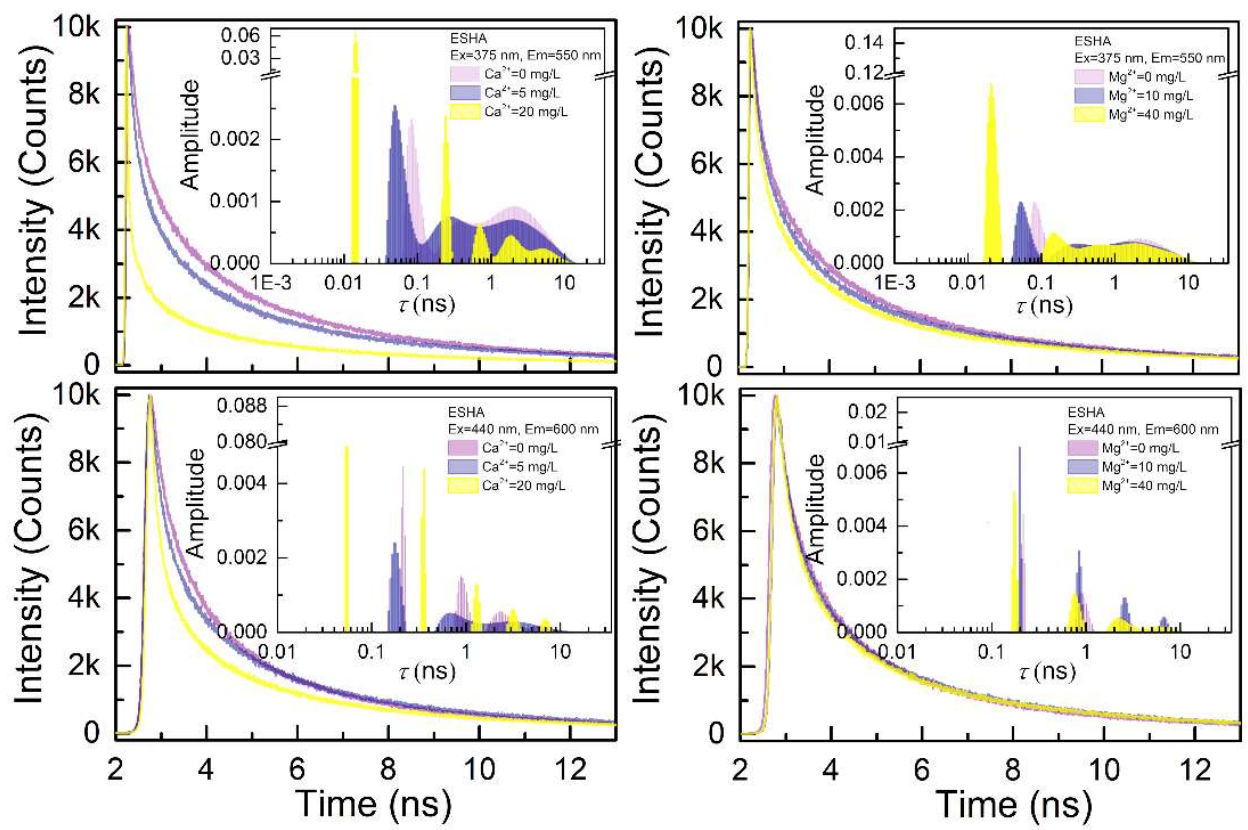

Figure 6. Effects of $\mathrm{Mg}^{2+}$ or $\mathrm{Ca}^{2+}$ concentrations on the lifetime distributions for emission decays of ESHA (10 mg C/L) aqueous solution at excitation of 375 and $440 \mathrm{~nm}$.

\section{Discussion}

\subsection{Binding of $\mathrm{Ca}^{2+}$ and $\mathrm{Mg}^{2+}$ to $\mathrm{CDOM}$}

Consistent with previous reports for other heavy metal ions [27], the binding affinity of $\mathrm{Ca}^{2+}$ and $\mathrm{Mg}^{2+}$ to terrestrial source CDOM was larger than that to aquatic source CDOM. Similar results were also reported for fluorescence quenching of CDOM by other organic quenchers [28], in which fluorescence of CDOM or its fractions with larger molecular size were more evidently quenched.

The binding constant of $\mathrm{Ca}^{2+}$ to $\mathrm{CDOM}$ was slightly smaller than that of $\mathrm{Cu}^{2+}$ reported [9,18-20]. Notably, CDOM used in this study differed from previous studies. Quenching of ESHA by $\mathrm{Cu}^{2+}$ was further investigated to exclude the effect of CDOM structure on the binding affinity. As shown in Figure S8, the fluorescence quenching efficiency for ESHA at emission wavelength longer than $600 \mathrm{~nm}$ by $10 \mathrm{mg} / \mathrm{L} \mathrm{Ca}^{2+}$ was approximately 1.5 times that by $0.3 \mathrm{mg} / \mathrm{L} \mathrm{Cu}^{2+}$, while the quenching efficiency for ESHA by $0.3 \mathrm{mg} / \mathrm{L} \mathrm{Cu}^{2+}$ was comparable to that by $50 \mathrm{mg} / \mathrm{L} \mathrm{Mg}^{2+}$. These results clearly supported the finding of a smaller $\lg K$ for $\mathrm{Cu}^{2+}$ to organic matter in a higher salinity water [9]. Moreover, due to diverse water hardness or other chemical compositions, the accuracy of quantifying CDOM or NOM concentration only by in-situ fluorescence spectrometry is doubtful.

\subsection{Process for fluoroscence quenching of CDOM by $\mathrm{Ca}^{2+}$ and $\mathrm{Mg}^{2+}$}

Fluorescence decays of fluorophore would not change in a typical static quenching process. Under the scenario of CDOM, the situation could be complex. Fluorescence decays became faster in the presence of cations, particularly in the case of $\mathrm{Ca}^{2+}$, leading to a decreased amplitude-weighted average lifetime $\left(\tau_{a}\right)$. The decrease of $\tau_{a}$ could result from several possibilities. 1) $\mathrm{Ca}^{2+}$ or $\mathrm{Mg}^{2+}$ quenched excited state of fluorophores in CDOM. 2) $\mathrm{Ca}^{2+}$ or $\mathrm{Mg}^{2+}$ formed complex with fluorophores with relatively long lifetime relative to fluorophores with relatively short lifetime. 3) Larger CDOM aggregates formed in the presence of $\mathrm{Ca}^{2+}$ or $\mathrm{Mg}^{2+}$, which could increase light scattering to some extent.

Under the first scenario, fluorophores with the longest lifetime were more likely involved in collisional quenching. However, as demonstrated in Figure 5 and Figure 6, 
lifetime distribution on the large value side has not shifted except for a decrease in their amplitude. For the component with a lifetime smaller than $1 \mathrm{~ns}$, collisional quenching was negligible when taking a millimolar $\mathrm{Ca}^{2+}$ or $\mathrm{Mg}^{2+}$ and a diffusion-controlled rate constant into account. Therefore, collision quenching was not the cause for the decrease of steadystate fluorescence intensity or acceleration of emission decay.

The second scenario requires fluorophores within CDOM were not equally quenched, which was supported by the dependence of quenching efficiency on excitation and emission wavelength (Figure S8). Moreover, as shown in inset Figure 6, amplitude for fluorophores with a lifetime longer than approximately $1 \mathrm{~ns}$ decreased with $\mathrm{Ca}^{2+}$ larger than $5 \mathrm{mg} / \mathrm{L}$. Therefore, the overall decay of CDOM became faster in the presence of $\mathrm{Ca}^{2+}$ or $\mathrm{Mg}^{2+}$. Moreover, the distribution of fluorophore lifetimes was more isolated in the presence of cations than in the absence of cations, indicating the complete quenching of some fluorophores or the interactions between fluorophores was weakened in the presence of $\mathrm{Ca}^{2+}$ or $\mathrm{Mg}^{2+}$.

The third scenario was supported by the different response of steady-state fluorescence intensity and emission decay to $\mathrm{Ca}^{2+}$ or $\mathrm{Mg}^{2+}$ concentration. For instance, steadystate fluorescence intensity of ESHA barely changed when $\mathrm{Ca}^{2+}$ or $\mathrm{Mg}^{2+}$ was higher than $20 \mathrm{mg} / \mathrm{L}$ or $40 \mathrm{mg} / \mathrm{L}$ (Figure 3), respectively. This result suggested that the composition or concentration of light-emitting fluorophores did not change, which conflicted with the further acceleration of emission decays. As shown in Figures S1 and S2, larger aggregates

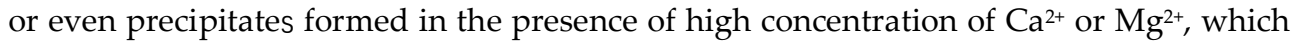
would increase light scattering that contributed to the fast decay component (Figure 6). Notably, formation of aggregates could lead to self-fluorescence quenching.

\subsection{The residues of CDOM fluorescence in the presence of $\mathrm{Ca}^{2+}$ and $\mathrm{Mg}^{2+}$}

Results obtained in this study show that CDOM maintained at least $10 \%$ percentage of its original steady-state fluorescence intensity among the conducted wavelength range. There are two candidates for the residual fluorescence. The first source is the unquenched fluorophore, and the second source is the metal-CDOM complex.

The first resource requires that some fluorophores are not accessible to metal ions or other quenchers. Recently, the lack of classical solvatochromism phenomena in CDOM optical spectra challenged the validation of charge-transfer model in interpreting the photophysical properties of CDOM [29], which put forward the argument that whether fluorophore responding for locally-excited states or charge transfer complex was freely diffusing and fully accessible [30,31]. As shown in Figures 5 and 6, fluorophores with long lifetime still presented in CDOM solution at high $\mathrm{Ca}^{2+}$ or $\mathrm{Mg}^{2+}$ concentration, which clearly showed that certain fluorophores were not accessible to these cations.

Notably, the distribution of ESHA's fluorescence lifetime shifted to the small value side in the presence of $5 \mathrm{mg} / \mathrm{L} \mathrm{Ca}^{2+}$. However, the shortest lifetime was still longer than 100 ps, which might not result from stray light. Therefore, metal-CDOM complex was also likely to contribute to residual fluorescence. Nevertheless, their contribution was minor because of their large deactivation rate constant.

\section{Conclusions}

Based on the change of optical spectra and hydrodynamic size of CDOM with $\mathrm{Ca}^{2+}$ and $\mathrm{Mg}^{2+}$, the current findings showed that both $\mathrm{Ca}^{2+}$ and $\mathrm{Mg}^{2+}$ had high binding constant to terrestrial source CDOM. The formation of metal-CDOM complex quenched CDOM fluorescence, whereas collisional quenching could not occur. Moreover, static quenching was more evident for fluorophores with relatively long lifetime. The excitation and emission wavelength dependent quenching efficiency suggested that fluorophores were quenched to different extents. Fluorophores with long lifetime were not fully quenched by $\mathrm{Ca}^{2+}$ or $\mathrm{Mg}^{2+}$, which suggested that metal-CDOM complex was not the only contributor to the unquenched fluorescence. 
Supplementary Materials: Figure S1: Absorption spectra of ESHA and PPHA (10 mg C/L) in the presence of $\mathrm{Mg}^{2+}$ and $\mathrm{Ca}^{2+}$, Figure S2: Effects of $\mathrm{Ca}^{2+}$ or $\mathrm{Mg}^{2+}$ on the hydrodynamic size of ESHA (60 $\mathrm{mg} \mathrm{C} / \mathrm{L}$ ) and PPHA (100 mg C/L) aqueous solution( $\mathrm{pH} 7.5)$, Figure S3: Effects of $\mathrm{Mg}^{2+}$ and $\mathrm{Ca}^{2+}$ on the EEM spectra of PPHA (10 mg C/L) aqueous solution, Figure S4: Effects of $\mathrm{Mg}^{2+}$ and $\mathrm{Ca}^{2+}$ on the steady-state fluorescence spectra of PPHA (10 mg C/L) aqueous solution at excitation of 375, 440, and $550 \mathrm{~nm}$, Figure S5: Effects of $\mathrm{Mg}^{2+}(10 \mathrm{mg} / \mathrm{L})$ or $\mathrm{Ca}^{2+}(10 \mathrm{mg} / \mathrm{L})$ on the time-resolved fluorescence spectra of PPHA (10 mg C/L) aqueous solution at excitation of 375 and $440 \mathrm{~nm}$, Figure S6: Lifetime distributions for emission decays of PPHA (10 mg C/L) aqueous solution at excitation of 375 and $440 \mathrm{~nm}, \mathrm{Mg}^{2+}(10 \mathrm{mg} / \mathrm{L}), \mathrm{Ca}^{2+}(10 \mathrm{mg} / \mathrm{L})$, Figure S7: Effects of $\mathrm{Mg}^{2+} \mathrm{Or} \mathrm{Ca}^{2+}$ concentrations on the lifetime distributions for emission decays of PPHA (10 mg C/L) aqueous solution at excitation of 375 $\mathrm{nm}$, Figure S8: Effects of excitation and emission wavelength on the fluorescence quenching of ESHA (10 mg C/L) aqueous solution by $\mathrm{Mg}^{2+}, \mathrm{Ca}^{2+}$, and $\mathrm{Cu}^{2+}$.

Author Contributions: Conceptualization, X.Z; methodology, J.L., X.Z.; formal analysis, J.L., R.Y.Z. X.Z.; investigation, J.L.; data curation, RY.Z, J.L., X.Z.; writing-original draft preparation, X.Z., J.L., R.Y.Z; writing - review and editing, X.Z., R.Y.Z, J.L; funding acquisition, X.Z. All authors have read and agreed to the published version of the manuscript."

Funding: This research was funded by National Natural Science Foundation of China, Grant No. 22076148 .

Conflicts of Interest: The authors declare no conflict of interest.

\section{References}

1. McNeill, K.; Canonica, S. Triplet state dissolved organic matter in aquatic photochemistry: reaction mechanisms, substrate scope, and photophysical properties. Environmental Science: Processes E Impacts 2016, 18, 1381-1399, doi:10.1039/C6EM00408C.

2. Davis, C.A.; Erickson, P.R.; McNeill, K.; Janssen, E.M.L. Environmental photochemistry of fenamate NSAIDs and their radical intermediates. Environmental Science: Processes E Impacts 2017, 19, 656-665, doi:10.1039/C7EM00079K.

3. Ossola, R.; Schmitt, M.; Erickson, P.R.; McNeill, K. Furan Carboxamides as Model Compounds To Study the Competition between Two Modes of Indirect Photochemistry. Environmental Science \& Technology 2019, 53, 9594-9603, doi:10.1021/acs.est.9b02895.

4. Chen, Y.; Zhang, X.; Feng, S. Contribution of the Excited Triplet State of Humic Acid and Superoxide Radical Anion to Generation and Elimination of Phenoxyl Radical. Environmental Science E Technology 2018, 52, 8283-8291, doi:10.1021/acs.est.8b00890.

5. Zheng, W.; Liang, L.; Gu, B. Mercury Reduction and Oxidation by Reduced Natural Organic Matter in Anoxic Environments. Environmental Science \& Technology 2012, 46, 292-299, doi:10.1021/es203402p.

6. Orsetti, S.; Marco-Brown, J.L.; Andrade, E.M.; Molina, F.V. Pb(II) Binding to Humic Substances: An Equilibrium and Spectroscopic Study. Environmental Science E Technology 2013, 47, 8325-8333, doi:10.1021/es400999q.

7. Wan, D.; Sharma, V.K.; Liu, L.; Zuo, Y.; Chen, Y. Mechanistic Insight into the Effect of Metal Ions on Photogeneration of Reactive Species from Dissolved Organic Matter. Environmental Science \& Technology 2019, 53, 5778-5786, doi:10.1021/acs.est.9b00538.

8. Xu, H.; Guan, D.-X.; Zou, L.; Lin, H.; Guo, L. Contrasting effects of photochemical and microbial degradation on Cu(II) binding with fluorescent DOM from different origins. Environmental Pollution 2018, 239, 205-214, doi:10.1016/j.envpol.2018.03.108.

9. Ryan, D.K.; Weber, J.H. Copper(II) complexing capacities of natural waters by fluorescence quenching. Environmental Science E Technology 1982, 16, 866-872, doi:10.1021/es00106a009.

10. Yan, M.; Dryer, D.; Korshin, G.V.; Benedetti, M.F. In situ study of binding of copper by fulvic acid: Comparison of differential absorbance data and model predictions. Water Research 2013, 47, 588-596, doi:10.1016/j.watres.2012.10.020. 
11. Li, T.; Song, F.; Zhang, J.; Tian, S.; Huang, N.; Xing, B.; Bai, Y. Experimental and modeling study of proton and copper binding properties onto fulvic acid fractions using spectroscopic techniques combined with two-dimensional correlation analysis. Environmental Pollution 2020, 256, doi:10.1016/j.envpol.2019.113465.

12. Ma, W.; Zhang, M.; Wang, R.; Xin, B.; Guo, W.; Dai, J. Mercury (II) Adsorption on Three Contrasting Chinese Soils Treated with Two Sources of Dissolved Organic Matter: II. Spectroscopic Characterization. Soil \& Sediment Contamination 2015, 24, 719-730, doi:10.1080/15320383.2015.1029607.

13. Guo, X.-j.; Li, Y.-z.; Feng, Y.-h.; Yuan, D.-h. Using fluorescence quenching combined with two-dimensional correlation fluorescence spectroscopy to characterise the binding-site heterogeneity of dissolved organic matter with copper and mercury in lake sediments. Environmental Chemistry 2017, 14, 91-98, doi:10.1071/en16135.

14. Wu, J.; Zhang, H.; He, P.-J.; Shao, L.-M. Insight into the heavy metal binding potential of dissolved organic matter in MSW leachate using EEM quenching combined with PARAFAC analysis. Water Research 2011, 45, 1711-1719, doi:10.1016/j.watres.2010.11.022.

15. Cuss, C.W.; Gueguen, C. Impacts of microbial activity on the optical and copper-binding properties of leaf-litter leachate. Frontiers in Microbiology 2012, 3, doi:10.3389/fmicb.2012.00166.

16. Wu, J.; Zhang, H.; Shao, L.-M.; He, P.-J. Fluorescent characteristics and metal binding properties of individual molecular weight fractions in municipal solid waste leachate. Environmental Pollution 2012, 162, 63-71, doi:10.1016/j.envpol.2011.10.017.

17. Fan, Y.; Zheng, C.; Huo, A.; Wang, Q.; Shen, Z.; Xue, Z.; He, C. Investigating the binding properties between antimony(V) and dissolved organic matter (DOM) under different $\mathrm{pH}$ conditions during the soil sorption process using fluorescence and FTIR spectroscopy. Ecotoxicology and Environmental Safety 2019, 181, 34-42, doi:10.1016/j.ecoenv.2019.05.076.

18. Lu, X.Q.; Jaffe, R. Interaction between $\mathrm{Hg}(\mathrm{II})$ and natural dissolved organic matter: A fluorescence spectroscopy based study. Water Research 2001, 35, 1793-1803, doi:10.1016/s0043-1354(00)00423-1.

19. Fu, P.; Wu, F.; Liu, C.; Wang, F.; Li, W.; Yue, L.; Guo, Q. Fluorescence characterization of dissolved organic matter in an urban river and its complexation with $\mathrm{Hg}(\mathrm{II})$. Applied Geochemistry 2007, 22, 1668-1679, doi:10.1016/j.apgeochem.2007.03.041.

20. Cabaniss, S.E. Synchronous Fluorescence Spectra of Metal-Fulvic Acid Complexes. Environmental Science E Technology 1992, 26, 1133-1139, doi:10.1021/es50002a018.

21. Power, J.F.; LeSage, R.; Sharma, D.K.; Langford, C.H. Fluorescence lifetimes of the well characterized humic substance, armdale fulvic acid. Environmental Technology Letters 1986, 7, 425-430, doi:10.1080/09593338609384429.

22. Chen, Y.; Liu, J.; Zhang, X.; Blough, N.V. Time-Resolved Fluorescence Spectra of Untreated and Sodium BorohydrideReduced Chromophoric Dissolved Organic Matter. Environmental Science \& Technology 2020, 54, 12109-12118, doi:10.1021/acs.est.0c03135.

23. Gao, Y.; Yan, M.; Korshin, G. Effects of calcium on the chromophores of dissolved organic matter and their interactions with copper. Water Research 2015, 81, 47-53, doi:10.1016/j.watres.2015.05.038.

24. Zang, Z.; Shi, W.; Ma, H.; Zhou, B.; Li, H.; Lu, C.; He, J. Binding Mechanism Between Fulvic Acid and Heavy Metals: Integrated Interpretation of Binding Experiments, Fraction Characterizations, and Models. Water Air and Soil Pollution 2020, 231, doi:10.1007/s11270-020-04558-2.

25. Kunhi Mouvenchery, Y.; Kučerík, J.; Diehl, D.; Schaumann, G.E. Cation-mediated cross-linking in natural organic matter: a review. Reviews in Environmental Science and Bio/Technology 2012, 11, 41-54, doi:10.1007/s11157-011-9258-3.

26. Luster, J.; Lloyd, T.; Sposito, G.; Fry, I.V. Multi-wavelength molecular fluorescence spectrometry for quantitative characterization of copper(II) and aluminum(III) complexation by dissolved organic matter. Environmental Science $\mathcal{E}$ Technology 1996, 30, 1565-1574, doi:10.1021/es950542u. 
27. Lee, Y.K.; Hur, J. Using two-dimensional correlation size exclusion chromatography (2D-CoSEC) to explore the sizedependent heterogeneity of humic substances for copper binding. Environmental Pollution 2017, 227, 490-497, doi:10.1016/j.envpol.2017.04.099.

28. Green, S.A.; Morel, F.M.M.; Blough, N.V. Investigation of the electrostatic properties of humic substances by fluorescence quenching. Environmental Science \& Technology 1992, 26, 294-302, doi:10.1021/es00026a008.

29. McKay, G.; Korak, J.A.; Erickson, P.R.; Latch, D.E.; McNeill, K.; Rosario-Ortiz, F.L. The Case Against Charge Transfer Interactions in Dissolved Organic Matter Photophysics. Environmental Science \& Technology 2018, 52, 406-414, doi:10.1021/acs.est.7b03589.

30. McKay, G.; Korak, J.A.; Erickson, P.R.; Latch, D.E.; McNeill, K.; Rosario-Ortiz, F.L. Response to Comment on The Case Against Charge Transfer Interactions in Dissolved Organic Matter Photophysics. Environmental Science \& Technology 2018, 52, 5514-5516, doi:10.1021/acs.est.8b01807.

31. Blough, N.V.; Del Vecchio, R. Comment on The Case Against Charge Transfer Interactions in Dissolved Organic Matter Photophysics. Environmental Science \& Technology 2018, 52, 5512-5513, doi:10.1021/acs.est.8b01189. 